\title{
THE INDIGENOUS AUSTRALIAN KNOWLEDGE TRADITIONS: NEW WAYS FOR OLD CEREMONIES - A CASE STUDY OF ABORIGINAL FINAL MORTUARY CEREMONIAL PRACTICES IN THE NORTHERN TERRITORY
}

\author{
Linda Payi Ford* \\ College of Indigenous Futures, Arts and Society, Charles Darwin University, \\ Northern Territory, NT 0909, Australia \\ E-mail: Linda.Ford@cdu.edu.au
}

Published online: 15 July 2020

To cite this article: Ford, L. P. 2020. The Indigenous Australian knowledge traditions: New ways for old ceremonies - A case study of Aboriginal final mortuary ceremonial practices in the Northern Territory. International Journal of Asia Pacific Studies 16 (2): 11-27. https://doi.org/10.21315/ijaps2020.16.2.2

To link to this article: https://doi.org/10.21315/ijaps2020.16.2.2

\begin{abstract}
Readers are alerted that the paper refers to Indigenous people who have passed away. The paper presents a detailed case study of ceremonial knowledge frameworks using an Indigenous research methodology based on Mirrwana and Wurrkama philosophy. This approach to case study research ensures the preservation, interpretation and dissemination of ceremonial performances recorded in the Wagait and Daly regions of the Northern Territory of Australia. The research focused on the corpus of Rak Mak Mak Marranunggu ceremonial metadata and was centred on the final mortuary cultural and ceremonial practices of Wali and Wangga ceremonies; the Wangga ceremony is often accompanied by the Lirrga and Djanba ceremonies of the neighbouring regions. The final mortuary ceremonial practices and performances were recorded by a research team from Charles Darwin University in 2007 and 2009. Included in the corpus of metadata were written records made by early anthropologists and missionaries in the Wagait and Daly regions. The results of this approach to Indigenous research are now shared. The Indigenous knowledge about these ceremonies is kept stored safely in several readily accessible
\end{abstract}


repositories whereby it is preserved, thereby extending the power of this knowledge for the benefit of Indigenous peoples and non-Indigenous peoples in Australia both now and into the future.

Keywords: Australian tradition, Indigenous Australian, mortuary practice, Wagait, Daly

\section{INTRODUCTION}

A research team lead by the author undertook to record, archive and protect Indigenous knowledge from the Wagait and Daly regions of the Northern Territory of Australia. The Indigenous knowledge central to this endeavour is that associated with the final mortuary cultural and ceremonial practices of Wangga, a ceremony often accompanied by the Lirrga and Djanba ceremonies of the neighbouring regions. The Wangga ceremony is integral to the custodial knowledge system of the Rak Mak Mak Marranunggu clan.

The overarching aim of the research was to ensure the long-term protection and succession of an oral tradition, Indigenous ceremonial knowledge, and knowledge expressed through Indigenous musicology traditions. Preserving and extending the power of these ceremonial practices was central to this research, with the aim of ensuring the ongoing benefits of this cultural knowledge for future generations of Indigenous peoples in Australia.

The research project had two key objectives. The first was to develop a digital resource (an internet repository) where Indigenous knowledge can be archived and readily accessed so that senior ceremonial leaders and younger generations are able to come together to understand and apply the recorded ceremonial knowledge into the future. The digitisation process was intended to create a living archive of the Wali, Wangga, Lirrga and Djanba ceremonies that will bridge the past and the future for both country and kin.

The second objective was to establish an appropriate framework to protect the links to historical recordings of the Wali and Wangga ceremonies and the accompanying Lirrga and Djanba ceremonies in the Wagait and Daly regions in the Northern Territory of Australia.

For Indigenous people, the creation of life is cherished by the whole community and country, because life comes from our mother Earth. For societies with oral traditions, the form of communication has been through songs, dance, chanting and signing performances and the rituals associated 
with these forms of communication linked to oral histories. In history, in humanity, these rituals were the universal claim of being human. For Mak Mak Marranunggu, these rituals are performed by oneself or in the company of two or more people. These ceremonies carry within them the knowledge of the people concerned. They are the lived "texts" through which cultural knowledge is both retained and transmitted to others.

In the past, the Wali, Wangga, Lirrga and Djanba ceremonies were under the strict control of the senior cultural leaders; the men and Koonie Koonie, women, of high intelligence and knowledge. In the Wagait and Daly regions these men were of the Marrawulgut nation consisting of Marranunggu and Marrithiyel language groups. Accompanying these male-controlled ceremonies was the Wali ceremony, which was under the control of the Koonie Koonie, senior women of high knowledge status.

The key issue driving our research was how to securely accommodate the public knowledge within these ceremonies in a form that could be transmitted beyond the living memories of these "clever men and women." This is an issue shared by all oral cultures, where the important knowledge that underpins each culture is carried within the memories of those community members with the responsibility of holding, preserving and then transmitting this knowledge to the next generation. With cultural dislocation and premature deaths, these bodies of knowledge can become fragile in terms of their survival and continuity through time (Ford et al. 2014; Corn and Ford 2014).

The research addressed this issue with the support of the relevant senior cultural ceremonial custodian and with the direction of the Koonie Koonie Daiyi, the senior woman whose final burial rites form the ceremonial context for the research. It was decided to establish a digital resource into which all accessible metadata relating to the Wali, and Wangga, Lirrga and Djanba ceremonies (as organised and performed during the final mortuary rites for Nancy Ngulikang Daiyi) were to be deposited for current and future generations of Mak Mak Marranunggu and other interested groups and individuals.

\section{MIRRWANA AND WURRKAMA PHILOSOPHY}

This was an Indigenous research project framed by the Mirrwana and Wurrkama philosophy of the Mak Mak Marranunggu (Ford 2005; Ford 2010; Ford et al. 2014). 
The Mirrwana is the cycad palm that nourishes the landscape of Mak Mak Marranunggu knowledge. This nourishment crystallises at ceremonial times, which are times of knowledge celebration and transmission. Wurrkama is the work done in the preparation of the cycad and its fruit, the pelanggu. Wurrkama involves caring for the country and preparing the pelanggu of the Mirrwana for consumption at the time of special ceremonial events.

The pelanggu is first collected from the Mirrwana after the country has been burnt to bring on the harvest. The gathered pelanggu is burst open to get the mimardi, the fruit's kernel. The mimardi are then crushed and wrapped in thiyel (paperbark) to form a wilan-bu package. The wilan-bu is placed in the water at the back of a billabong (wurda-rtadi) for the water to leach out the toxins in the mimardi. Time is given for the leaching to occur with careful checking and replacement of thiyel. When sufficient time has passed, the mimardi is ground on grinding stones and left to dry out to form a flour meal. The final stage of the preparation is accomplished when the meal is baked into lawa (a sweet flatbread) and served on mulangi leaves to those attending the ceremony. Eating the lawa sustains those taking part in the ceremony.

Mirrwana and Wurrkama come together at these important ceremonial events to ensure closure and to encourage new beginnings in the learning journeys of the participants nurtured by the knowledge contained in, and carried by, the music of the ceremonies themselves (Ford 2005; Ford 2010: 68; Rose et al. 2010: 28; Ford et al. 2014: 43).

The author applied this Mirrwana and Wurrkama philosophy as a central Indigenous knowledge metaphor to frame the process of making a space for Indigenous knowledge in the landscape of the higher education curriculum (Ford 2005; 2010; Ford et al. 2014: 43). Other Indigenous women, Joanne Gurngulkpuy and Elaine Lawurrpa Maypilama of North Eastern Arnhem Land, have developed their own Indigenous knowledge metaphors for educational and research processes referred to as "Yalu Marngithingyaraw Research Methodology" (Gurngulkpuy and Maypilama 2005: 1). For example, the Garnggulk hunting metaphor was developed by Yolngu researchers at Charles Darwin University to theorise their research processes.

In the country of the Mak Mak Marranunggu, women have played, and continue to play, significant roles in public ceremonies and in maintaining the continuity of traditional sacred law (Corn and Ford 2014: 125). Therefore, it was appropriate for the research team to be led by the author, an Indigenous Mak Mak Marranunggu woman for this project. 


\section{A CASE STUDY}

This paper is presented as a case study of an Indigenous research methodology applied to the recording, archiving and preservation of Tyikim (Indigenous) ceremonial knowledge; in this case, the knowledge associated with the final mortuary rites of the Mak Mak Marranunggu clan and of related peoples of the Wagait and Daly regions of the Northern Territory. The Mirrwana and Wurrkama philosophy provided the Indigenist theory for the research (Ford $2005 ; 2010)$.

The evidentiary database the research team both created and accessed, was a body of recordings of the mortuary rites of the Indigenous people of the Wagait and Daly region. This database contained both historical and contemporary recordings. The research team had, from these recordings, a corpus of metadata pertaining to the Mak Mak Marranunggu final mortuary cultural practices and ceremonies.

The projects Indigenous research methodology started by treating the body of recordings of the ceremonies and the metadata as the equivalent of the unprocessed pelanggu. Pelanggu is not edible without this transformative processing. The individual pieces of information, recordings dispersed both in time and filing location, needed to be assembled in one place and treated in various ways so as to be re-archived and available for re-use in an easily accessible form. The process was analogous to the ways in which the pelanggu is processed before being eaten, and ingested, as lawa.

Throughout the process, the narratives and performances recorded by the research team, together with the historical archival information, have been examined through a Reflective Bio-ethnographic lens (Ford 2005; 2010) with special attention to the following "Tyikim pedagogical principles":

- Valuing and sharing Tyikim [Indigenous] knowledge

- Acknowledging the relationship between country and knowledge

- Recognising that relationships and interconnectedness are essential and fundamental to Tyikim people

- Addressing Tyikim community business

- Adopting a Tyikim research methodology

- Prioritising Tyikim knowledge bearers (Ford 2005: 194; 2010: 152). 
These principles allowed members of the research team to work and operate in a parallel space that brought multiple layers of relationships and cultural contexts to bear on the interpretation of the ceremonies referred to in the archive more broadly.

The re-archiving process involved an innovative mapping of the corpus of ceremonial recordings and other related materials. This mapping involved seeking out historical records as well as preparing for contemporary ceremonies followed by harvesting, management, ingestion and dissemination processes akin to Mirrwana and Wurrkama processes for managing Tyikim Indigenous knowledge. This mapping process was aimed at decolonising the abstraction of Indigenous-related archival materials that occurs within non-Indigenous institutions (Nakata 2007; Nakata and Langton 2005).

The corpus of ceremonial recordings and other related materials, the project's "Ceremony Collection," emerged from the research as an Indigenous knowledge website of re-archived resources: a digitised repository of Rak Mak Mak Marranunggu ceremonial knowledge.

Figure 1 maps the journey taken by the research team paralleling the processes within Mirrwana and Wurrkama.

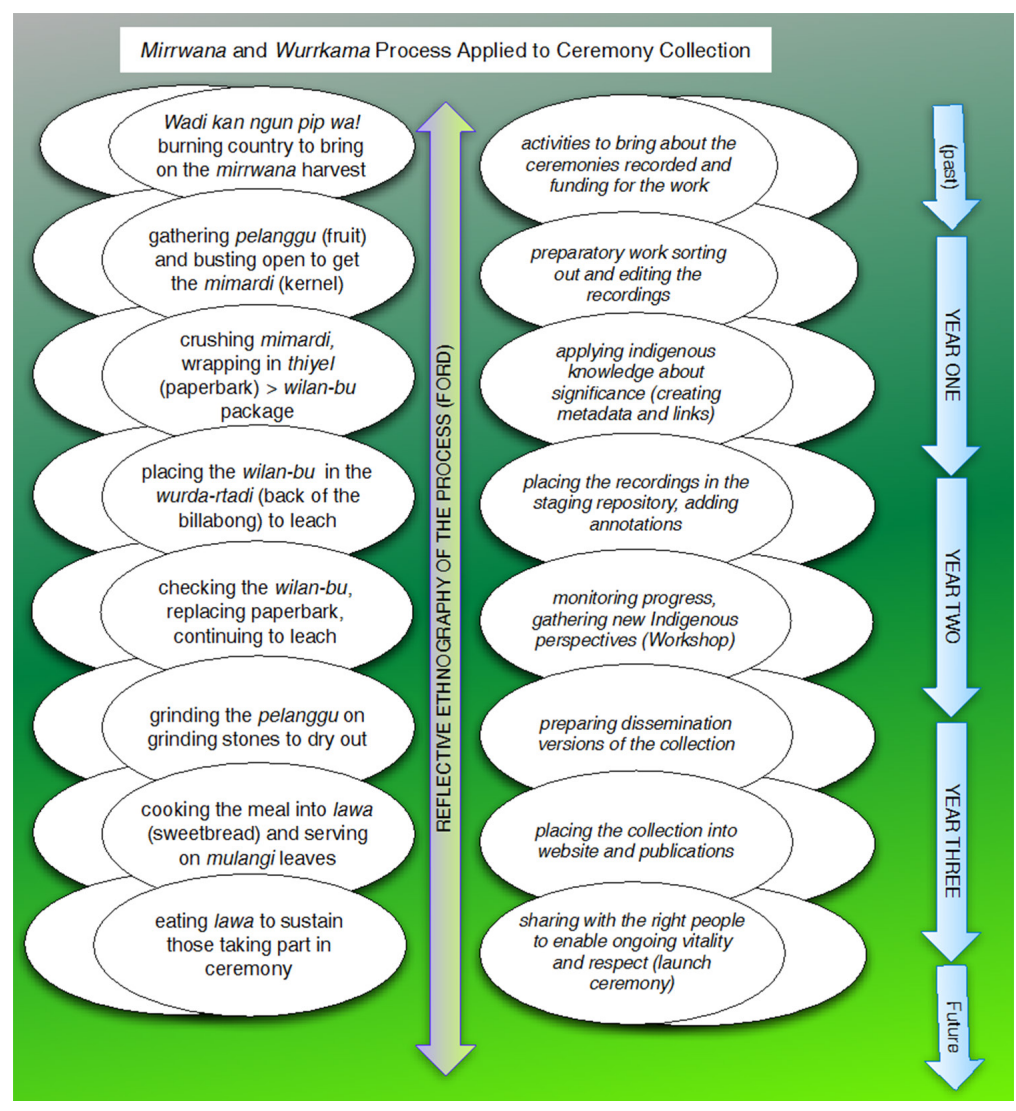

Figure 1: The embedding of the work of the project over three years within the framework of the Mirrwana and Wurrkama Indigenous research methodology. 


\section{THE RESEARCH TEAM}

Linda Payi Ford from Charles Darwin University was the principal researcher and was supported by the Indigenous ceremonial families and the academic advisory committee members. The research project was undertaken from 2007 to 2009.

\section{THE APPROACH TAKEN}

The research team applied a three-step planned approach that examined and compared records of old ceremonies with contemporary practices. These steps were:

1. Examination of the historical body of records dating from 1869 to 2014;

2. Documentation of the existing metadata corpus of ceremonial knowledge (recordings of the original ceremonies, together with subsequent responses and teachings from the senior ceremonial leaders recorded by the author in 2012); and

3. Generation of new layers of interpretation through interviews and discussions with the remaining ceremonial participants from the Wagait and Daly regions (singers, dancers and Rak Mak Mak Marranunggu clan members and family). This step was difficult due to the death of participants in two ceremonial performances highly relevant to the project, those in 2007 and 2009. Due to cultural reasons the project team did not pursue family members to interview them due to community events that were not conducive to undertaking the research in remote areas of the Northern Territory.

\section{THE "CEREMONY COLLECTION"}

The ceremonial knowledge associated with the final mortuary rites of the Rak Mak Mak Marranunggu clan is based upon the ancient oral traditions of Indigenous peoples. This oral tradition is therefore the dominant paradigm for the assimilation and incorporation of Indigenous knowledge from the past and into the present and onto the future. The research team respected this paradigm in its work of creating a corpus of ceremonial knowledge associated with the final mortuary rites of the Rak Mak Mak Marranunggu clan and translating this knowledge into a contemporary digital archive. 
Central to the "Ceremony Collection" was a body of recordings of final mortuary ceremonies recorded in 2007 and 2009 funded by a 2007 Australian Research Council grant. A secondary source of data consisted of historical recordings of Rak Mak Mak Marranunggu mortuary practices and of those of other Indigenous peoples in from the Wagait and Daly regions. These prior recordings were in the form of documents produced by non-Indigenous observers; that is, by early settlers, surveyors, police, anthropologists and missionaries residing in or visiting the Wagait and Daly regions. Together these recordings constituted the corpus of data, the project's "Ceremony Collection."

\section{THE SECONDARY SOURCES OF DATA}

The research project allowed additional researchers Emily Ford, Chloe Ford and Jodie Kell to examine and index the materials and documents available for preservation in the re-archived digitised repository overseen by Linda Barwick and Linda Payi Ford.

The research team located the first photographic documentation of the mortuary ceremonial practices of Indigenous peoples of the Wagait and Daly regions recorded by Police Inspector Paul Foelsche (1889). This photographic record was in Foelsche's photographic collection in the Northern Territory Police archives at the National Archives and the Northern Territory Archives. In 1889 and onwards, the local Palmerston newspaper also recorded an account of a photograph taken by Foelsche of a deceased Aborigine on a platform identified by the policeman in charge as a Larrakia.

The Jesuit Missionaries made diary entries from 1891 to 1899 of mortuary practices in the Daly region, albeit with reference to "pagan ideology" (Jesuit Missions Records n.d.). However, the descriptions were not detail enough to contribute significant Indigenous knowledge other than the fact that Indigenous people did practice platform burials and these ceased to be common practice with the arrival of non-Indigenous people.

An Aboriginal platform burial was recorded by non-Indigenous persons that was by the native patrol officer and the policeman from Brocks Creek on the Finniss River on 17 September 1930.

Patrolled to small plain about $1 / 2$ mile from mine with a couple of witnesss and viewed a body up on a platform of a dead aboriginal which boys declared was "Barney Charling" deceased in the left side 
of the spine I noticed a big gash about 4 inches long $\& 2$ inches wide. Body practically withered up (Northern Territory Police Journals, 17 September 1930 in the NT Archives).

This recorded event complements the Rak Mak Mak Marranunggu oral history traditions relating to Walangurmingy, a site of significance where platform burials were undertaken. This connection between the Brocks Creek record and Walangurmingy is supported by the documentation recorded in the Finniss River Land Claim, 1981, evidence presented by anthropologist Peter Sutton and the Rak Mak Mak Marranunggu claimants, Fred Waters, Peter Melyen, Bilawuk Kirol, Pandela Clayton and Nancy Ngulilkang Daiyi.

\section{THE CENTRAL SOURCE OF DATA}

The central sources of data and the key principal resource are the recordings of Rak Mak Mak Marranunggu ceremonial performances in 2007 and 2009. These final mortuary ceremonies had never been previously recorded in the manner captured in this principal resource. The integration of these recordings into the repository represents extremely important Indigenous ceremonial knowledge from the different domains within the Wagait and Daly regions of the Northern Territory.

On 4 April 2007, Nancy Ngulilkang Daiyi, a highly knowledgeable elder of the Rak Mak Mak Marranunggu clan, passed away. Prior to her death, Daiyi, in her instructions to her daughter, Linda Payi Ford, included a culturally appropriate approach to engage the senior cultural ceremonial leader to carry out the ceremonies as well as to preserve her Indigenous knowledge traditions. She gifted the ceremonial knowledge about how her daughter Payi was to conduct the final mortuary rites for her and she provided her daughter with a list of rituals to undertake for the duration of the ceremony process.

In 2009, the author facilitated a three-day ceremony celebrating the final mortuary rites (mitharr). All ceremonial leaders attending practised the Wali, Wangga, Djanba and Lirrga ceremonial traditions of the Daly and Wagait regions. The ceremony was designed and carried out following instructions from our region's senior cultural ceremonial custodian and leader F. Dumoo (d. December 2012), and by Captain Wodidj and from Payi Ford's mother herself. 
The body of recordings, in the form of films, audio recordings and photographs, were documented for Nancy Ngulilkang Daiyi's family by research team members Linda Barwick, Allan Marett, Sally Treloyn and Mark Ford as the ceremonies were performed. These ceremonial performances included songs, dances and other ritual actions at two places in Rak Mak Mak Marranunggu traditional country - Kurrindju in the Wagait area and the Meneling burial ground near Batchelor. This was the first time in four decades that the full traditional rituals for mitharr had been performed in this region.

The specific song traditions requested by Daiyi were from the ceremony groups of Wangga, Djanba and Lirrga. This final mortuary ceremony was a complex ceremony requiring extensive regional coordination and participation. The public ceremonial dances and songs of the Daly and Wagait regions have been systematically recorded and documented by the author and their collaborators over the past 20 years; however, the Wangga, Djanba and Lirrga ceremonies are rarely performed in the one setting (Barwick 2004; 2006; Barwick and Marrett 2011; Barwick et al. 2007; Ford 2005; Marett 2005).

As such, this occasion represented a significant learning opportunity for all participants, and especially for the younger generations of the clans who (following traditional practice) were drawn in to the event from the wider Daly and Wagait regions (Berndt 1951; Elkin 1957; Falkenberg 1962; Marett et al. 2014; Poirier 1992).

The final song of the Wangga, Djanba, and Lirrga ceremonial groups, the Walakandha, was sung on the 31 July 2009 for Ahla (Mum) for her journey to the next place on country:

WW12 (composed by Thomas Kungiung)

karra walakandha ngindji kiny warri kurzi kubuwemi nidinngin-a

A certain Walakandha is living there for a whole year. Kubuwemi! My dear country!

karra ngatha devin bugim rtadi-nanga kuwa. kubuwemi nidinngin-a

There is a solitary house with a white roof there. Kubuwemi! My dear country!

(Kungiung, Barwick and Marett 2009) 


\section{Developing the Digital Resource (An Internet Repository)}

This project provided a rich opportunity to apply a significant Indigenous knowledge metaphor to frame the process of creating a space for the unique body of recordings of a highly significant event. In contrast to traditional ethnographic approaches to the documentation of ceremonies, dances and songs, the research conducted in this project was from the perspective of an "insider." Therefore, the research emphasises the links between country, kin and knowledge that are empowered through ceremonial action.

The project collaborators included Indigenous researchers, Indigenous Cultural Consultants, other Specialist Experts, the senior authorities, and the younger ceremonial owners who collectively took part in the documentation, transcription and translation processes to create the digital resource. Additionally, participants engaged in a way that encouraged the theorisation and implementation of digital technologies for the intergenerational transmission of ceremonial practices.

Advice and support were provided by Rak Mak Mak Marranunggu people, academics at the Northern Institute at Charles Darwin University, University of Sydney, University of New South Wales and University of Melbourne, librarians and archivists from across Australia. The author established an expert advisory group, whose members already had longstanding and successful collaborative relationships and were knowledgeable about ceremonies central to the research.

The author, while being guided by the Mirrwana and Wurrkama philosophy, developed a Reflective Bio-ethnography Workflow Model through which to engage with the "Ceremonial Collection" (see Figure 2).

The Reflective Bio-ethnography Workflow Model is a process that engages Indigenous paradigms of old and new contemporary methods to preserve and maintain what Indigenous knowledge is available. The Reflective Bio-ethnography approach is generative and functions from the ground up, from the community through to academia and onto repositories of Indigenous knowledge in a virtual abstract space of technology and digitisation. The Reflective Bio-ethnography Workflow Model is a powerful tool for Indigenous people to work collaboratively to deconstruct the processes of the past, analyse content to make sense of metadata and to interpret with a present-day lens that allows the continuation of the transmission of Indigenous knowledge practices from one generation to the next. 


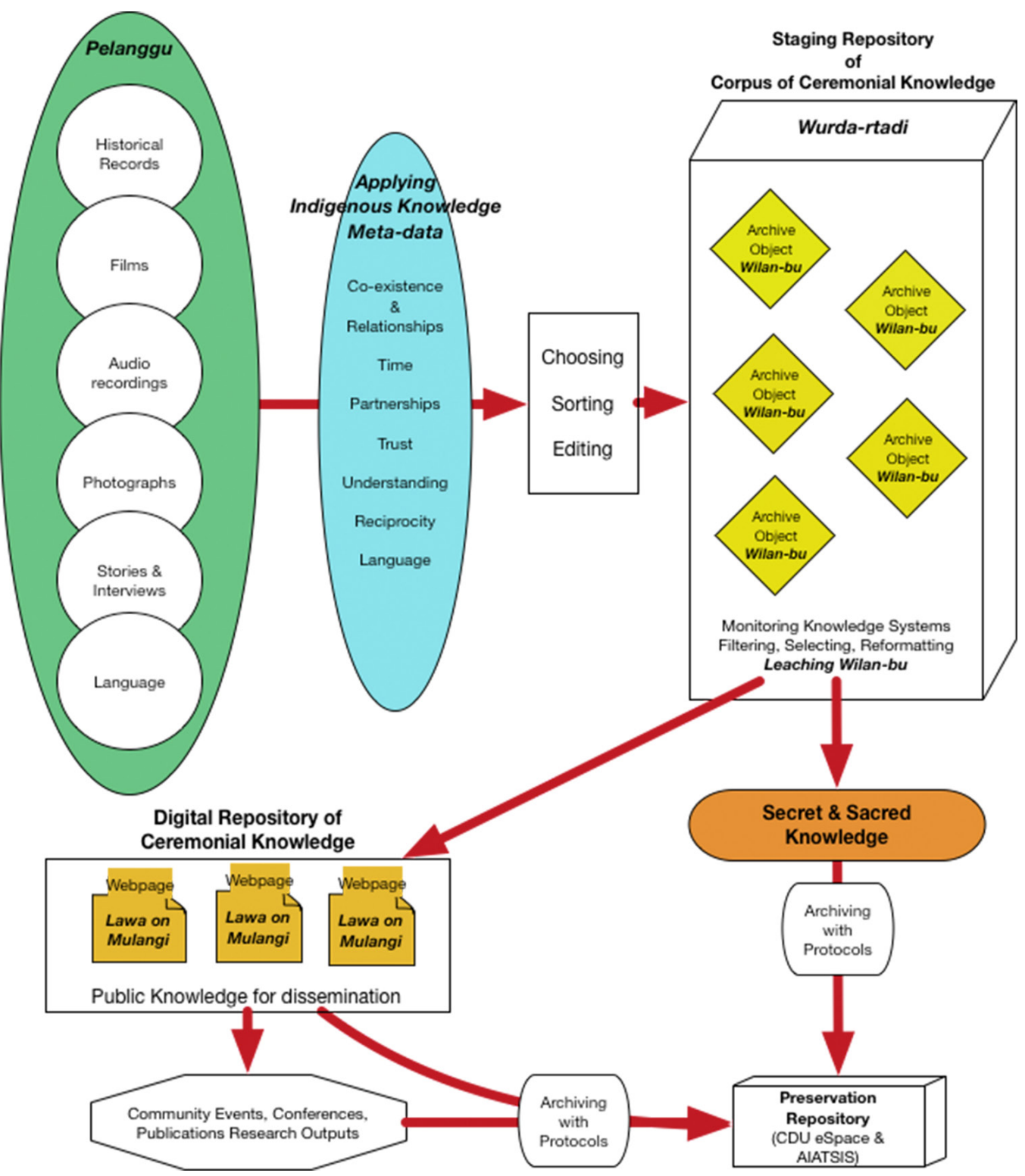

Figure 2: The Reflective Bio-ethnography Workflow Model (Ford 2005; 2010; Ford et al. 2014).

To ensure the integrity of the historical metadata from 1869 to 2014 , the archived materials were examined and indexed for re-archiving in the digitised repository. These records are now accessible online through Pacific and Regional Archive for Digital Sources in Endangered Cultures (PARADISEC) at the University of Sydney and at Charles Darwin University eSpace. Many of these indexed files can also be accessed from the National Archives, the Northern Territory Archives, museums nationally, public libraries and the Australian Institute of Aboriginal and Torres Strait Islander Studies (AIATSIS). The only materials not accessible by the general public are those archived files listed as "restricted." 
The recordings have been indexed and annotated using standard annotation packages and formats (e.g., emulated local area network or ELAN, and other multi-media open-source linguistic annotation software) that produce Extensible Markup Language (XML) files with time codes for significant events. ELAN also allows for different layers of interpretation so that the comments of different practitioners (e.g., the ceremonial leaders and younger people encountering these ceremonial practices for the first time) contribute to the rich contextualisation of the ceremonial knowledge available through the event and the recordings. Workflows were developed within PARADISEC and other digital archives of similar content to create web objects (such as subtitled videos) by combining media with the standardised annotations.

The body of existing recordings of ceremonial practices was examined and annotated by the senior ceremonial leaders to document them ready for future reference. Furthermore, where it was appropriate, the custodians of these ceremonies authorised those areas within the Indigenous knowledge files that were appropriate for publication, to share with the general public. Restrictions apply to other materials that will be of vital interest to future generations of Indigenous ceremonial practitioners, and these materials have been prepared for archiving in a suitable restricted repository such as the AIATSIS.

The digitised materials in the resultant internet repository demonstrate the significance of this Rak Mak Mak Marranunggu clan ceremony. The repository affords Mak Mak and other guests to the repository the opportunity to draw comparisons between the new contemporary final mortuary ceremonial practices and the old.

As represented in Figures 1 and 2, the research team developed an innovative methodology for mapping the available corpus of ceremonial knowledge, mapping which was embedded within the Mirrwana and Wurrkama framework for managing Tyikim knowledge. By framing its mapping processes as Indigenous knowledge, the study established and documented a workflow model for further use and development by Indigenous researchers.

\section{IMPACT OF THE PROJECT}

The applied Indigenous research methodology employed in this project retrieved many archived files relevant to the Rak Mak Mak Marranunggu final mortuary ceremonial performances along with recordings of a 2009 ceremony and interviews with key descendants of the deceased Nancy Ngulilkang Daiyi. 
Included in the methodology was the application of a workflow model termed the Reflective Bio-ethnography approach (Ford 2005; 2010; Ford et al. 2014) with key descent members and those with shared responsibilities to undertake the role to disseminate the materials and records located in the repository.

The research has preserved the power of the ceremony to ensure the long-term succession of Indigenous knowledge in Australia through intergenerational transmission of oral and documented ceremonial knowledge. As the materials were discovered by the research team, the author was able to interpret the recordings and documents for members of the following generation of Rak Mak Mak Marranunggu - Emily Ford, Chloe Ford and Nicole Thompson. These younger Rak Mak Mak Marranunggu are also Assistant Researchers and local Indigenous Cultural Consultants. Thus, the oral traditions of Rak Mak Mak Marranunggu are sustained in the present by Mak Mak Marranunggu family members led by Linda Payi Ford. The principal cohort of Rak Mak Mak Marranunggu is the Indigenous knowledge custodians of the internet repository of Indigenous knowledge. These Indigenous custodial cohorts have a shared responsibility and ownership of the digitised and hard copies of the materials deposited, including the Finniss River Land Claim evidence presented in 1981.

\section{CONCLUSION}

The project enhanced the researchers' capacity to manage digital technologies in the service of intergenerational transmission of ceremonial practices aligning with studies of Aboriginal and Torres Strait Islander society and with Indigenous knowledge perspectives. The project activities enacted and gave life to the connections and knowledge that hold together people; country, kin and stories within the framework of ceremonies past, present and future, across cultures, languages and spirituality in ways that had not been imagined.

The corpus of knowledge deposited in the archives can now be accessed in central locations in Darwin and Sydney managed by the Mak Mak Marranunggu custodial group, PARADISEC, the AIATSIS and the Northern Institute at Charles Darwin University.

Anticipated uses of the materials contained in the repository include packages aimed at higher education (research and teaching). The site will be available to inform the general public nationally, internationally and importantly at the local level about traditional mortuary practices. The site will preserve for future generations old ceremonies in new ways. A list of useful 
materials, reports and books such as Country of the Heart: An Indigenous Australian Homeland (Rose et al. 2010) are accessible.

The significance of the knowledge transmission will be through the cross-generational transfer of ceremonial knowledge both within the Rak Mak Mak Marranunggu clan and participating clans throughout the Wagait and Daly regions of the Northern Territory, and possibly, other Indigenous clans across Australia.

Australia's Indigenous spirituality and ceremonial knowledge are unique and the project created a diverse array of interpretations and understandings of ceremonial practices significant to Indigenous Australians. These interpretations and understandings empower Indigenous Australians to participate fully in national dialogue about their knowledge and its significance. The ongoing cross-generational re-invigoration of ceremonial knowledge through performance needs ongoing support and resourcing.

This research applied an innovative Indigenous research methodology to gather and present information about Indigenous knowledge. Ultimately, the knowledge accessed to promote a better understanding of the significance of Indigenous knowledge in contemporary Australia, knowledge celebrating an Indigenous cultural heritage of 80,000 years.

\section{NOTES}

* Linda Payi Ford is a Rak Mak Mak Marranunggu woman. Her country is Kurrindju in the Finniss River and Reynold River regions south west of Darwin in the Northern Territory. Associate Professor Ford is a Principal Research Fellow in the Northern Institute at Charles Darwin University in the College of Indigenous Futures, Arts and Society located in Darwin, Northern Territory, Australia. Her transdisciplinary approach to research and education enable her to operate across the diversity of the cross-cultural contexts and their practices locally, nationally and internationally. The ground-up method she applies to the new ways for old ceremonies case study designedbased research integrates an approach that enables an applied Indigenous research practice and theory to be actioned in a decolonised framework. 


\section{REFERENCES}

Barwick, L. 2004. Turning it all upside down... Imagining a distributed digital audiovisual archive. Literary and Linguistic Computing 19(3): 253-263. https://doi.org/10.1093/ $11 \mathrm{c} / 19.3 .253$

2006. Marri Ngarrlirrga songs: A musicological analysis of song pairs in performance. Musicology Australia 28: 1-25. https://doi.org/10.1080/08145857.2 005.10415276

Barwick, L. and Marett, A. 2011. Aural snapshots of musical life: Simpson's 1948 recordings. In Exploring the legacy of the Arnhem land expedition in 1948: Science, diplomacy and aboriginal studies in a transnational context, eds. Thomas, M. and Neale, M., 355-375. Canberra: ANU Press. https://doi.org/10.22459/elale.06.2011.18

Barwick, L. et al. 2007. Arriving, digging, performing, returning: An exercise in rich interpretation of a Djanba song text in the sound archive of the Wadeye Knowledge Centre, Northern Territory of Australia. In Oceanic music encounters: The print resource and the human resource: Essays in honour of Mervyn McLean, ed. Moyle, R. M., 13-24. Auckland: Anthropology Department, University of Auckland.

Berndt, R. M. 1951. Ceremonial exchange in Western Arnhem land. Southwestern Journal of Anthropology 7 (2): 156-176. https://doi.org/10.1086/soutjanth.7.2.3628621

Corn, A. and Ford, P. L. 2014. Consensus and collaboration in the making of the national recording project for Indigenous performance in Australia. In Collaborative ethnomusicology: New approaches to music research between indigenous and non-indigenous Australians, ed. Barney, K., 115-128. Melbourne: Lyrebird Press.

Elkin, A. P. 1957. Arnhem land volume 1: Authentic aboriginal songs and dances [12-inch 33rpm disc, with notes]. Sydney: EMI (Australia) OALP7504.

Finniss River Land Claim: Report by the Aboriginal Land Commissioner, Mr. Justice Toohey, to the Minister for Aboriginal Affairs and to the Administrator of the Northern Territory. 1981. Canberra: Australian Government Publishing Service.

Falkenberg, J. 1962. Kin and totem: Group relations of Australian aborigines in the Port Keats district. Oslo: Oslo University Press. https://doi.org/10.1525/ aa.1962.64.6.02a00200

Ford, L. M. 2005. Narratives and landscapes: Their capacity to serve indigenous knowledge interests. $\mathrm{PhD}$ diss., Deakin University.

Ford, P. L. 2010. Aboriginal knowledge narratives and country: Marri Kunkimba Putj Putj Marrideyan. Brisbane: Post Pressed. https://doi.org/10.1017/s1326011100000211

Ford, P. L., Barwick, L. and Marett, A. 2014. Mirrwana and Wurrkama: Applying Indigenous knowledge framework to collaborative research on ceremonies. In Collaborative ethnomusicology: New approaches to music research between Indigenous and nonIndigenous Australians, ed. Barney, K., 43-62. Melbourne: Lyrebird Press.

Gurngulkpuy, J. and Maypilama, L. E. 2005. Yalu marngithingyaraw research methodology. Darwin: Charles Darwin University.

Jesuit Missions Records: Excerpt from Jesuit Missions Records - Rum Jungle. n.d. The Archives of the Australian Province of the Society of Jesus, Melbourne, Australia.

Kungiung, T., Barwick, L. and Marett, A. 2009. Recording of WW12 (composed by Thomas Kungiung): Karra walakandha ngindji kiny warri kurzi kubuwemi nidinngin- $a$. University of Sydney. 
Marett, A. 2005. Songs, dreamings and ghosts: The Wangga of North Australia. Middletown, CT: Wesleyan University Press.

Nakata, M. 2007. The cultural interface. Australian Journal of Indigenous Education 36S, 7-13.

Nakata, M. and Langton, M. (Eds.). 2005. Australian Indigenous knowledge and libraries. Canberra: Australian Academic and Research Libraries. https://doi.org/10.1080/ 00048623.2005.10721248

Northern Territory Police Journals. 1930. Death recorded - Brock's Creek, 17 September 1930. Northern Territory Archives, NT.

Poirier, S. 1992. "Nomadic" rituals: Networks of ritual exchange between women of the Australian Western Desert. Man 27 (4): 757-776. https://doi.org/10.2307/2804173

Rose, D. et al. 2010. Country of the heart: An indigenous homeland, 2nd ed. Canberra: Aboriginal Studies Press. 